\title{
Tying the Politicians'
}

Hands: The Optimal Limits

to Representative Democracy

DIDIER LAUSSEL

NGO VAN LONG 
2019s-14

\title{
Tying the Politicians' Hands: The Optimal Limits to Representative Democracy
}

\author{
Didier Laussel, Ngo Van Long
}

\section{Série Scientifique \\ Scientific Series}

\author{
Montréal \\ Juillet/July 2019
}

(C) 2019 Didier Laussel, Ngo Van Long. Tous droits réservés. All rights reserved. Reproduction partielle permise avec citation du document source, incluant la notice (C. Short sections may be quoted without explicit permission, if full credit, including (C) notice, is given to the source.

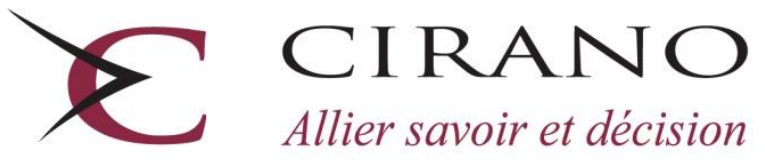

Centre interuniversitaire de recherche en analyse des organisations 


\section{CIRANO}

Le CIRANO est un organisme sans but lucratif constitué en vertu de la Loi des compagnies du Québec. Le financement de son infrastructure et de ses activités de recherche provient des cotisations de ses organisations-membres, d'une subvention d'infrastructure du gouvernement du Québec, de même que des subventions et mandats obtenus par ses équipes de recherche.

CIRANO is a private non-profit organization incorporated under the Quebec Companies Act. Its infrastructure and research activities are funded through fees paid by member organizations, an infrastructure grant from the government of Quebec, and grants and research mandates obtained by its research teams.

\section{Les partenaires du CIRANO}

\section{Partenaires corporatifs}

Autorité des marchés financiers

Banque de développement du Canada

Banque du Canada

Banque Laurentienne

Banque Nationale du Canada

Bell Canada

BMO Groupe financier

Caisse de dépôt et placement du Québec

Canada Manuvie

Énergir

Hydro-Québec

Innovation, Sciences et Développement économique Canada

Intact Corporation Financière

Investissements PSP

Ministère de l'Économie, de la Science et de l'Innovation

Ministère des Finances du Québec

Mouvement Desjardins

Power Corporation du Canada

Rio Tinto

Ville de Montréal

\section{Partenaires universitaires}

École de technologie supérieure

École nationale d'administration publique

HEC Montréal

Institut national de la recherche scientifique

Polytechnique Montréal

Université Concordia

Université de Montréal

Université de Sherbrooke

Université du Québec

Université du Québec à Montréal

Université Laval

Université McGill

Le CIRANO collabore avec de nombreux centres et chaires de recherche universitaires dont on peut consulter la liste sur son site web.

Les cahiers de la série scientifique (CS) visent à rendre accessibles des résultats de recherche effectuée au CIRANO afin de susciter échanges et commentaires. Ces cahiers sont écrits dans le style des publications scientifiques. Les idées et les opinions émises sont sous l'unique responsabilité des auteurs et ne représentent pas nécessairement les positions du CIRANO ou de ses partenaires.

This paper presents research carried out at CIRANO and aims at encouraging discussion and comment. The observations and viewpoints expressed are the sole responsibility of the authors. They do not necessarily represent positions of CIRANO or its partners.

ISSN 2292-0838 (en ligne) 


\title{
Tying the Politicians' Hands: The Optimal Limits to Representative Democracy
}

\author{
Didier Laussel ${ }^{*}$, Ngo Van Long ${ }^{*}$
}

\begin{abstract}
The citizen-candidate models of democracy assume that politicians have their own preferences that are not fully revealed at the time of elections. We study the optimal delegation problem which arises between the median voter (the writer of the constitution) and the (future) incumbent politician under the assumption that not only the state of the world and but also the politician's type (preferred policy) are the policy-maker's private information. We show that it is optimal to tie the hands of the politician by imposing both a policy floor and a policy cap and delegating him/her the policy choice only in between the cap and the floor. We establish two uncertainty principles: (a) the state-uncertainty principle, which states that the greater is the uncertainty about the state of the world, the wider is the delegation interval, and (b) the bias-uncertainty principle, which states that the greater is the uncertainty about political bias, the smaller is the delegation interval.
\end{abstract}

Keywords: Representative Democracy, Optimal Delegation, Political Uncertainty, Policy Caps, Policy Floors, Citizen Candidates

JEL Codes: D82, H10

\section{Résumé}

Les récents modèles de la démocratie supposent que les hommes politiques ont leurs propres préférences qui ne sont pas pleinement révélées au moment des élections. Nous étudions le problème de délégation optimale qui se pose entre le votant médian (l'auteur de la constitution) et le (futur) politicien sous l'hypothèse que non seulement l'état du monde mais aussi le type de politicien sont des informations privées. Nous montrons qu'il est optimal de lier les mains du politicien en lui imposant à la fois un plancher et un plafond, et en lui déléguant le choix politique seulement entre le plafond et le plancher. Nous établissons deux principes d'incertitude : (a) le principe d'incertitude des états, selon lequel plus l'incertitude sur l'état du monde est grande, plus l'intervalle de délégation est large, et (b) le principe d'incertitude sur les biais, qui exige que l'intervalle de délégation soit une fonction décroissante de l'incertitude sur le type du politicien.

Mots-clés : Démocratie représentative, Délégation optimale, Incertitude politique, Plafonds de politique, Planchers de politique, Candidats citoyens

Codes JEL : D82, H10

\footnotetext{
*Aix-Marseille University, CNRS, EHESS, Centrale Marseille, AMSE. Email: didier.laussel@outlook.fr

${ }^{\dagger}$ Department of Economics, McGill University. Email: ngo.long@mcgill.ca
} 


\section{Introduction}

Representative democracy may be best defined as a political system in which the power to choose public policies is delegated to elected representatives (which we will call here "politicians" for short). The main alleged advantage of representative democracy is that representatives are able to specialize in policy-making. This allows them to devote more time to study the state of the world than ordinary citizens and thus to make better informed decisions.

Given the number and the complexity of public decisions to be taken in a modern society, the advantages of representative democracy are so important that in one way or another all modern democracies are basically representative democracies, with sometimes some elements of direct or participative democracy like referendums and/or popular initiatives. It has however long been recognized that this system has costs of its own. The main drawback of representative democracy is that representatives are free, once elected, to promote their own interests. Representatives cannot be bound by a binding mandate; indeed they cannot commit to implement specific policies once elected because it is impossible to write complete contracts describing what the representatives should do in each of the multitude of circumstances that could occur during their term of office.

The purpose of the present paper is to study the optimal constitutional limits, depending on the relative precision of voter information regarding the optimal public policies and that regarding the valence of incumbent politicians. We construct a specific delegation problem which belongs to a class of principal-agent problems dealing with settings in which, according to Amador and Bagwell (2013) "a principal faces an informed but biased agent, and contingent transfers between the principal and the agent are infeasible." Indeed, political settings are highly relevant examples of this kind of problems where legal rules limit or even completely forbid transfers to elected representatives. The type of delegation problem we analyze in our paper has a novel feature. While our model and the existing models share a common feature, namely, the agent (the incumbent politician) has private information about 
the state of the world, and her preference is generally biased with respect to that of the prin$\operatorname{cipal}^{1}$, our model differs from most existing models (with the exception of Armstrong, 1995) by assuming that the principal does not know the direction and magnitude of the agent's bias. $^{2}$ The representative's type as determined by the electoral process is a random variable. (We do not model the electoral process here; we simply treat it a black box in order to focus on the delegation problem.) Throughout this paper we restrict attention to the case where there is more uncertainty about the state of the world than about the politician's preferences. For the sake of simplicity, we suppose that the voting procedure is unbiased, in the sense that the expected representative's type is the median voter's type.

Our contribution is to characterize the optimal delegation for the senario in which the representative's bias is random while the electoral process is unbiased. We show that the policy choice should then be delegated to the elected representative only within bounds: an upper bound (policy cap) and a lower bound (policy floor). Cap and floor are imposed to avoid extreme policy choices under delegation. Our main result is that the writer of the constitution always finds it optimal to tie the hands of future politicians in this way. Furthermore, we show that the interval of parameter values over which delegation occurs shrinks when the political uncertainty increases. These results clearly apply to many other contexts, and not just to the specific problem studied in our model.

In order to focus on the delegation issue when the future politician's type is private information, we have abstracted from a number of considerations. First, in our formal model, the incumbent is free from re-election concerns. We have not taken into account the fact that the desire to be re-elected might significantly mitigate the politician's imperfect alignment of interests with the median voter. Second, we have assumed that constitutional rules are sharply defined. In practice, most rules are not fully spelled out, and need to be interpreted by a Constitution Court (in the USA, the Supreme Court).

\footnotetext{
${ }^{1}$ The principal is here the writer of the constitution. Throughout the paper we call him/her the median voter though this coincidence may be true only initially.

${ }^{2}$ We thank a reviewer for referring us to Armstrong's working paper of on this topic. In section 2, we elaborate on the difference between Armstrong (1995) and our model.
} 
Our paper main's insight is that the constitution shall rule out extreme policies or extreme actions. In practice, of course, policy limits are subject to the interpretations of Constitutional Courts (or the Supreme Court, in the case of the USA), and constitutions are subject to amendments. In Germany, the Balanced Budget Amendment to Germany's Basic Law was added in 2009, stipulating that Germany's federal government cannot run a structural deficit of more than $0.35 \%$ of GDP, while permitting an exception for larger deficits in cases of emergencies or severe economic crises. In defence matters, Germany's federal government has the duty to its citizens of maintaining an army for self defence, and yet at the same time, a number of Constitutional Court cases established that the government cannot deploy the armed forces outside of NATO zone without a specific resolution of the parliament. Internally, military personnels cannot be used for police-type duties. Similar upper and lower bounds in defence matters are found in Japan's constitution (Hughes, 2006). In the USA, it has been pointed out that while the President can freely sack his Attorney General without any explanation, he does not have the same power over the (lower-level) US Attorneys. Indeed, Congress possesses the constitutional authority to restrain the president's removal of US Attorneys within the limits established by separation of power principles and the Supreme Court's removal power jurisprudence (Weiss, 2008).

The rest of this paper is organized as follows. Section 2 contains a brief review of the related literature. Section 3 outlines the model. Section 4 analyzes two benchmark cases. Section 5 characterizes the equilibria of the general model. Section 6 is reserved for fuller discussions on constitutional limitations and other applications of our model.

\section{Related literature}

The view that representative democracy derives its advantage from specialization of labor dates back to at least 200 years ago. ${ }^{3}$ The risk of preference divergence between the politician

\footnotetext{
${ }^{3}$ For an insightful comparison between representative democracy and direct democracy, see Benjamin Constant (1819, p. 16). The debate on their relative merits has recently been revived after the Brexit referendum. See, for example, Peter Singer (2016), among others.
} 
and the people was expressed forcefully by Jean-Jacques Rousseau (1762) who argued that even when there a coincidence between what the constituency and their representatives want at the time the former delegates their power to the latter, there is nothing to ensure that this coincidence will continue. The principle of separation of powers is arguably a safeguard against the non-alignment of interests between the politicians and the people (Hamilton, Madison, and Jay, 1788/1961).

The non-congruence between policies adopted by politicians and the preferences of the electorate has been well established in the literature. Indeed, it is well known that even if the election is a single issue one (one-dimensional policy space) there may be multiple voting equilibria as soon as there are more than two candidates. Moreover, when the policy space is multi-dimensional, the voters have to choose between packages: there is nothing to ensure that on each issue the elected representative's proposed policies are the ones that a majority prefers. ${ }^{4}$ Three recent examples are relevant. In France, although President Macron was elected by a large majority, the elimination of the wealth tax (Impôt de Solidarité sur la Fortune), although present in his election platform, is opposed by a majority of French voters. Similarly, US President Trump's project of repealing Obamacare is opposed by a majority of US voters. In Germany, Angela Merkel's preference regarding the number of refugees to be admitted is arguably different from that of the median voter (Hillman and Long, 2018).

There are several strands of literature on policy choice that are related to our model. Starting from Osborne and Slivinski (1996) and Besley and Coate (1997), the economic literature has developed an alternative theory of policy choice in representative democracies, i.e., models in which "citizen candidates" run for election. These models depart from the traditional Hotelling model of electoral competition (Downs, 1957) in two important respects: (i) the citizens-candidates have policy preferences instead of being exclusively office-motivated,

\footnotetext{
${ }^{4}$ More generally, McKelvey (1976, p. 472) has shown that in the case of multi-dimensional policy spaces "it is theoretically possible to design voting procedures which, starting from any given point, will end up at any other point in the space of alternatives, even at Pareto dominated ones."
} 
and (ii) they cannot commit to implement any policy other than their most preferred one. These models have been extended to a setting where each candidate's ideal point is his/her private information (Großer and Palfrey, 2009, 2014, 2017). While this literature focuses on the electoral process, its conclusions confirm the existence of political uncertainty: there are generally multiple equilibria and the type of the elected representative cannot be predicted with certainty. Indeed, this literature shows that the elected politician's type almost always differs from the median voter's type.

Our model is closer to the political agency models, which deal with the relationship between citizens/voters (the principals) and the politicians/government (the agent). This literature encompasses moral hazard models where politicians may use their office to extract rents (Ferejohn, 1986; Hillman, 2018; Persson and Tabellini, 2000), and adverse selection models where the issue is to select the 'good' politicians (Besley and Prat, 2004). There are also models which combine moral hazard and adverse selection (Besley and Case, 1995; Coate and Morris, 1995; Fearon, 1999, among others). A basic element of these models is the idea that politicians may be made accountable to the citizens via electoral competition. ${ }^{5}$ While a politician's concern for reelection does act as a discipline device, these models find that it does not ensure full accountability. Indeed, Fearon (1999) finds that voters are better off using elections as a device for selecting types, rather than for disciplining incumbents. In the same vein, Besley (2006, p. 111) concludes that the reelection mechanism is imperfect since it is unable to always eliminate dissonant politicians. Moreover, Coate and Morris (1995) find that political competition does not prevent inefficient methods of redistribution to be employed. This is clearly in line with our assumptions about the existence and persistence of political uncertainty.

Finally, our paper has much in common with the papers on optimal delegation problem

\footnotetext{
${ }^{5}$ On political accountability, see Przeworski et al. (1999). For a review of recent theoretical and empirical research on electoral accountability, see Ashworth (2012). Of note is the array of various alternative approaches to explaining why an incumbent might have incentives to act contrary to voters' interests. These include signaling models and multi-task models. In contrast to the two-period models surveyed by Ashworth, there is also a strand of literature that assumes repeated electoral competition: see, for example, Duggan and Feys (2006) and Banks and Duggan (2008).
} 
(e.g., Holmström, 1977 and 1984) that focus on "interval delegation", i.e., the set over which the policy choice is delegated to the agent is a single interval. Other papers on optimal delegation have provided conditions for the optimality of interval delegation under various settings. In Amador, Werning and Angeletos (2006), the present self delegates to the future self the future consumption/saving decision; Alonso and Matouschek (2008) studied the issue of how to regulate the future regulators; Ambrus and Egorov (2009) obtained specific results by assuming uniform distributions and quadratic utility functions. A recent paper by Amador and Bagwell (2013) provides necessary and sufficient conditions which encompass previous results as special cases. ${ }^{6}$ Our paper differs from this literature by analyzing the case where the agent's bias is a random variable whose realized value is private information of the agent. To the best of our knowledge, the only theoretical work that has formally addressed this issue is the working paper by Armstrong (1995). However, Armstrong stated explicitly that he assumed, rather than proved, that the principal allows the agent to use discretion only over an interval. Also, Armstrong focused mostly on a "reduced-form" behavior function for the agent and on comparative statics across agent types.

\section{The political economy setting}

In modern democracies, there are rules that deny politicians the right to make certain choices. To explain how such rules arise, we consider a stylized model of a representative democracy operating under a written constitution. We abstract from the process of constitutional debates, amendments, and interpretation of the constitution. We present a model in which the median voter acts as the principal that designs rules to be obeyed by the agent (the future elected politicians). The rules specify what the politicians can do and what they cannot do. Rules are instituted as a safeguard against politicians who might act according to their own interests. While in the real world constitutional rules are subject to interpretations, in our model we suppose that rules are sharply defined. Real world examples of sharply defined

\footnotetext{
${ }^{6}$ Koessler and Martimort (2012) studied the case when the decision space is two-dimensional. They assumed quadratic utility functions and uniform distribution of the agent's type.
} 
constitutional rules are indeed rare. Often constitutional courts (in the case of the USA, the Supreme Court) must decide whether a particular piece of legislation or policy action violates the rules. ${ }^{7}$ In this section, we present a parsimonious model of constitutional limitations on policy choices.

A policy $x$ has to be chosen from a feasible set $X=\left[x_{L}, x_{H}\right]$ which is a closed interval of the real line. As usual in this literature on delegation, to avoid the prolification of cases to be considered, we assume that the set $X$ is sufficiently large, so that all politicians' and voters' preferred policies are in the interior of this set. There is a continuum of voters, with preferences indexed by a scalar $t$, which is symmetrically distributed along the real interval $[-\delta, \delta]$. The population mass is normalized to unity. A politician is elected from this set of voters. The utility function of a voter (or a potential politician) whose preference is $t$ is given by the quadratic function

$$
u(x ; t, \theta)=(B+\theta+t) x-\frac{1}{2} x^{2}
$$

where $B$ is a constant, and $\theta$ denotes the state of the world (with expected value $E \theta=0$ ). The set of all possible states of the world is the real interval $[-\varepsilon, \varepsilon]$. Our utility specification means that in the case of the median voter (the person whose $t$ is zero), the most preferred policy in state $\theta$ is $x^{*}(\theta ; t=0)=B+\theta$, which implies that, on average, her ideal value of $x$ is $B$. When the state of the world is $\theta=\varepsilon$, the most preferred policy of a voter with the extreme rightist preference, $t=\delta$, is $B+\varepsilon+\delta$, and when the state of the world is $\theta=-\varepsilon$, the most preferred policy of a voter with the extreme leftist preference, $t=-\varepsilon$, is $B-\varepsilon-\delta$. For mathematical simplicity, we assume that $x_{L}<B-\varepsilon-\delta$ and $x_{H}>B+\varepsilon+\delta$, which means that there are feasible policies that no voter or politician would ever want.

To take a concrete example, one may suppose that $x$ is the government annual spending on defence. On average, the median voter wants this spending level to be $B$. However, if the external threat is higher than average (i.e., if $\theta>0$ ), she would want higher defence spending, while if $\theta<0$, she would want lower defence spending. The term $(1 / 2) x^{2}$ represents the per

\footnotetext{
7 Section 6 discusses these matters in greater details.
} 
capita cost of financing the defence spending (this cost may include the deadweight losses that arise when spending is financed by means of distortionary taxes).

Denote by $\phi(\theta)$ the probability density function for $\theta$. Assume that $\phi(\theta)$ is strictly positive only for $\theta$ belonging to the real interval $[-\varepsilon, \varepsilon]$. Consider a voter whose preference parameter $t$ takes on the lowest value, $-\delta$. In the event of extremely low external threat $(\theta=-\varepsilon)$, her most-preferred defence spending level would be $x^{*}(-\varepsilon ; t=-\delta)=B-(\delta+\varepsilon)$. Alternatively, consider a voter whose preference parameter $t$ takes on the highesr value, $\delta$. In the event of extremely high external threat $(\theta=\varepsilon)$, his most-preferred defense spending level would be $x^{*}(\varepsilon ; t=\delta)=B+(\delta+\varepsilon)$.

We assume that voters (as opposed to elected politicians) do not have information about the realized value of $\theta$. Then, under direct democracy, the median voter would choose $x$ to maximize his expected utility, $B x-\frac{1}{2} x^{2}$, that is, he would vote for $x=B$. Following the insight of Benjamin Constant, we assume that politicians, thanks to their specialization, are perfectly informed about $\theta$.

We consider a principal-agent model where the median voter is the principal and the politician is the agent. At the time when the decision on $x$ must be taken, $\theta$ is not known to the voters, but it is known to the incumbent politician. An elected politician of type $t \in[-\delta, \delta]$ has the utility function ${ }^{8}$

$$
U(x ; t, \theta)=(B+\theta+t) x-\frac{1}{2} x^{2} .
$$

Following the political economy approach, we suppose that politicians maximize their utility. If the incumbent politician were unconstrained in her decision making, then, given that she has private information about the realized $\theta$, she would choose $x$ to maximize her own utility, knowing that her type is $t$. This means that she would choose

$$
x=B+\theta+t
$$

\footnotetext{
${ }^{8}$ One could add a constant $R$ to the utility function, which represents a direct benefit from being in office, i.e., the "spoils of office" (Osborne and Slivinski, 1996, p. 65), which possibly include the "ego-rent" of being the occupier of a prestigious position (Rogoff, 1990).
} 
while the interest of the median voter is best served if $x=B+\theta$. If $t \neq 0$, we say that the politician is biased (relative to the median voter's preference). ${ }^{9}$ A positive $t$ means the politician's bias is toward the right (e.g., she would like to spend more on defence than the median voter would want). Similarly, a negative $t$ means that the politician's bias is toward the left.

\subsection{The median voter's problem}

The politician knows her type $t$, but the voters do not: they only know that $t$ is distributed with a probability density function $\psi(t)$, where $t \in[-\delta, \delta]$. At the time when the decision on $x$ must be made, $\theta+t$ is the politician's private information. Define

$$
\alpha=\theta+t
$$

Then the density function for $\alpha$, denoted by $f(\alpha)$, is the convolution $(\phi * \psi)(\alpha)$, i.e.,

$$
f(\alpha)=(\phi * \psi)(\alpha) \equiv \int_{-\infty}^{\infty} \phi(\theta) \psi(\alpha-\theta) d \theta
$$

In what follows, we assume that $\phi$ and $\psi$ are uniform density functions, i.e.,

$$
\begin{gathered}
\phi(\theta)=\left\{\begin{array}{cc}
0 & \forall \theta<-\varepsilon \\
\frac{1}{2 \varepsilon} & \forall \theta \in[-\varepsilon, \varepsilon] \\
0 & \forall \theta>\varepsilon
\end{array}\right. \\
\psi(t)=\left\{\begin{array}{cc}
0 & \forall t<-\delta \\
\frac{1}{2 \delta} & \forall t \in[-\delta, \delta] \\
0 & \forall t>\delta
\end{array}\right.
\end{gathered}
$$

Given the uniform density functions $\phi$ and $\psi$, the convolution (2) can be computed as follows. For any given $\alpha \in[-\varepsilon-\delta, \varepsilon+\delta]$, let us denote by $D(\alpha)$ the set of $\theta$ values that are consistent with $t \in[-\delta, \delta]$, i.e.,

$$
D(\alpha) \equiv\{\theta \in[-\varepsilon, \varepsilon] \mid-\delta \leq \alpha-\theta \leq \delta\}
$$

\footnotetext{
${ }^{9}$ For example, when a politician is of type $t=\delta$ (the most extreme right-wing type), upon observing that $\theta=\varepsilon$, she will choose the defence spending level $x=B+\varepsilon+\delta$ if she is unconstrained in her choice. But any spending level greater than $B+\varepsilon$ is never in the best interest of the median voter.
} 
Then

$$
f(\alpha)=\int_{D(\alpha)} \frac{1}{4 \delta \varepsilon} d \theta
$$

Using (4), we find that $\alpha$ has the following trapezoid-shaped density function

$$
f(\alpha)=\left\{\begin{array}{c}
\frac{\varepsilon+\delta+\alpha}{4 \varepsilon \delta}, \forall \alpha \in[-\varepsilon-\delta, \delta-\varepsilon] \\
\frac{1}{2 \varepsilon}, \forall \alpha \in[\delta-\varepsilon, \varepsilon-\delta] \\
\frac{\varepsilon+\delta-\alpha}{4 \varepsilon \delta} \forall \alpha \in[\varepsilon-\delta, \varepsilon+\delta]
\end{array},\right.
$$

and consequently, the corresponding cumulative distribution function is

$$
F(\alpha)=\left\{\begin{array}{c}
\frac{(\varepsilon+\delta+\alpha)^{2}}{8 \varepsilon \delta}, \forall \alpha \in[-\varepsilon-\delta, \delta-\varepsilon] \\
\frac{\alpha+\varepsilon}{2 \varepsilon}, \forall \alpha \in[\delta-\varepsilon, \varepsilon-\delta] \\
\frac{-\alpha^{2}+2(\delta+\varepsilon) \alpha-\varepsilon^{2}-\delta^{2}+6 \delta \varepsilon}{8 \varepsilon \delta}, \forall \alpha \in[\varepsilon-\delta, \varepsilon+\delta]
\end{array} .\right.
$$

Given any prescribed schedule $x($.$) that associates to each \alpha \equiv \theta+t$ an action $x(\alpha)$, the expected utility of the median voter is

$$
W^{M}=\int_{-\delta}^{\delta}\left[\int_{-\varepsilon}^{\varepsilon}\left((B+\theta) x(\theta+t)-\frac{1}{2}(x(\theta+t))^{2}\right) \frac{1}{2 \varepsilon} d \theta\right] \frac{1}{2 \delta} d t
$$

This expected utility may be conveniently rewritten as

$$
W^{M}=E[(B+\theta) x]-\frac{1}{2} E\left[x^{2}\right]
$$

where

$$
E\left[x^{2}\right] \equiv \int_{\underline{\alpha}}^{\bar{\alpha}}\left[x(\alpha)^{2}\right] f(\alpha) d \alpha \equiv \int_{-\varepsilon-\delta}^{\varepsilon+\delta}\left[x(\alpha)^{2}\right] f(\alpha) d \alpha
$$

and

$$
\begin{aligned}
E[(B+\theta) x] & \equiv \int_{-\delta}^{\delta}\left[\int_{-\varepsilon}^{\varepsilon}(B+\theta) x(\theta+t) \frac{1}{2 \varepsilon} d \theta\right] \frac{1}{2 \delta} d t \\
& =\int_{-\varepsilon-\delta}^{\varepsilon+\delta} x(\alpha)\left[\int_{D(\alpha)} \frac{(B+\theta)}{4 \delta \varepsilon} d \theta\right] d \alpha
\end{aligned}
$$

where $D(\alpha)$ is given by eq. (3).

Since $\alpha$ is the politician's private information, the median voter's problem of expected utility maximization is a principal-agent problem. The median voter must design a schedule $x($.$) that is incentive-compatible to the agent. Applying the revelation principle, the median$ voter's optimization problem can be formulated as follows. 
Problem 1: Choose a function $x($.$) that maximizes (8), subject to the incentive-$ compatibility constraint: an agent that has private information $\alpha$ will choose action $x(\alpha)$ in preference to any other action $x(\widehat{\alpha})$, i.e., ${ }^{10}$

$$
\alpha=\arg \max _{\widehat{\alpha}}\left[(B+\alpha) x(\widehat{\alpha})-\frac{1}{2}(x(\widehat{\alpha}))^{2}\right] .
$$

\subsection{Properties of incentive-compatible schedules in the absence of transfers}

Before fully characterizing the solution of Problem 1, we must state a number of properties that any incentive-compatible scheme $x($.$) must satisfy, given that transfers are not feasible.$ The median voter, as principal, offers the elected politician a schedule $x(\alpha)$. To fix ideas, suppose the median voter writes a constitution which in effect tells the elected politician the following message: "Here is the schedule (the function) $x($.$) defined over the set of possible$ values of $\alpha \in[-\varepsilon-\delta, \varepsilon+\delta]$. You must report a value $\widehat{\alpha}$ belonging to this set. If your report is $\widehat{\alpha}$, you will be required to take action $x(\widehat{\alpha})$." Clearly, a schedule $x($.$) is able to induce the$ agent to report $\alpha$ truthfully if and only if under that schedule, the agent cannot obtain a better payoff by reporting a false value $\widehat{\alpha} \neq \alpha$. Let $\pi^{A}(\widehat{\alpha}, \alpha)$ denote the agent's payoff, where $\alpha$ is the true value and $\widehat{\alpha}$ is the reported value:

$$
\pi^{A}(\widehat{\alpha}, \alpha)=(B+\alpha) x(\widehat{\alpha})-\frac{1}{2} x(\widehat{\alpha})^{2}
$$

Let $W^{A}(\alpha)$ denote the politician's optimized utility under an incentive-compatible schedute $x($.$) , when her private information is \alpha$. Recall that a schedule $x($.$) induces truth telling if$ and only if for each $\alpha$, we have $W^{A}(\alpha) \equiv \pi^{A}(\alpha, \alpha) \geq \pi^{A}(\widehat{\alpha}, \alpha)$ for all $\widehat{\alpha} \in[-\varepsilon-\delta, \varepsilon+\delta]$. That is,

$$
W^{A}(\alpha)=(B+\alpha) x(\alpha)-\frac{1}{2} x(\alpha)^{2} \geq(B+\alpha) x(\widehat{\alpha})-\frac{1}{2} x(\widehat{\alpha})^{2}
$$

\footnotetext{
${ }^{10}$ Unlike the standard (text-book) principal agent model with transfers between the principal and the agent, here the principal does not receive nor make transfers from/to the agent.
} 
By a standard revealed preference argument, any incentive-compatible schedule $x(\alpha)$ is nondecreasing for all $\alpha \in[-\varepsilon-\delta, \varepsilon+\delta]$. The reason why $x(\alpha)$ must be non-decreasing is straightforward: any politician that observes a higher $\alpha$ will want to choose a higher $x$. Therefore any schedule that is decreasing in $\alpha$ over some range of $\alpha$ will not be able to induce the politician to report the true $\alpha$.

As is well known, due to Berge's maximum theorem, the optimized objective function $W^{A}(\alpha)$ is a continuous function of $\alpha$. Furthermore, over any interval $\left(\alpha_{1}, \alpha_{2}\right)$ where $x(\alpha)$ is differentiable, since $\pi^{A}(\widehat{\alpha}, \alpha)$ is maximized at $\widehat{\alpha}=\alpha$, the following first order condition must hold, where $x(\widehat{\alpha})$ is evaluated at $\widehat{\alpha}=\alpha$,

$$
[(B+\alpha)-x(\alpha)] \frac{d x}{d \alpha}=0
$$

that is, either $x(\alpha)=B+\alpha$ or $d x / d \alpha=0$ on $\left(\alpha_{1}, \alpha_{2}\right)$. We report this result as Property 1 .

Property 1: Schedules that are incentive-compatible must be non-decreasing and almost everywhere differentiable. Over any interval of differentiability $\left[\alpha_{0}, \alpha_{1}\right]$, either $x(\alpha)=B+\alpha$, or $x(\alpha)$ is a constant all $\alpha \in\left[\alpha_{0}, \alpha_{1}\right]$. In other words, over any interval of differentiability $\left[\alpha_{0}, \alpha_{1}\right]$ either the politician is free to do what she likes, or she is constrained to take a constant action.

Applying the envelope theorem to (12), we find that

$$
\frac{d W^{A}}{d \alpha}=\frac{\partial \pi^{A}(\widehat{\alpha}, \alpha)}{\partial \alpha}=x(\widehat{\alpha}) \text { where } \widehat{\alpha}=\alpha
$$

It follows from (15) that the following two equations hold:

$$
\begin{aligned}
& W^{A}(\alpha)=W^{A}(\underline{\alpha})+\int_{\underline{\alpha}}^{\alpha} \frac{d W^{A}\left(\alpha^{\prime}\right)}{d \alpha^{\prime}} d \alpha^{\prime}=W^{A}(\underline{\alpha})+\int_{\underline{\alpha}}^{\alpha} x\left(\alpha^{\prime}\right) d \alpha^{\prime} \\
& W^{A}(\alpha)=W^{A}(\bar{\alpha})-\int_{\alpha}^{\bar{\alpha}} \frac{d W^{A}\left(\alpha^{\prime}\right)}{d \alpha^{\prime}} d \alpha^{\prime}=W^{A}(\bar{\alpha})-\int_{\alpha}^{\bar{\alpha}} x\left(\alpha^{\prime}\right) d \alpha^{\prime}
\end{aligned}
$$

where $\underline{\alpha} \equiv-\varepsilon-\delta$, and $\bar{\alpha} \equiv \varepsilon+\delta$. It is important to note that we cannot treat $W^{A}(\underline{\alpha})$ and $W^{A}(\bar{\alpha})$ as constant. We will determine these values endogenously, as part of the optimization problem of the median voter. ${ }^{11}$

\footnotetext{
${ }^{11}$ See the proof of Proposition 1.
} 
In general, an incentive-compatible schedule $x($.$) , while being non-decreasing and almost$ everywhere differentiable, may exhibit an upward jump discontinuity. At any point $\widetilde{\alpha} \in$ $(-\varepsilon-\delta, \varepsilon+\delta)$ where there is an upward jump, we denote by $x^{-}(\widetilde{\alpha})$ and $x^{+}(\widetilde{\alpha})$ respectively the limit from the left and the limit from the right:

$$
\lim _{\alpha \uparrow \widetilde{\alpha}} x(\alpha) \equiv x^{-}(\widetilde{\alpha})<x^{+}(\widetilde{\alpha}) \equiv \lim _{\alpha \downarrow \widetilde{\alpha}} x(\alpha)
$$

Since $W^{A}(\alpha)$ is continuous, the following relationship holds at any point $\widetilde{\alpha}$ where $x($.$) has$ an upward jump:

$$
W^{A}(\widetilde{\alpha})=(B+\widetilde{\alpha}) x^{-}(\widetilde{\alpha})-\frac{1}{2}\left(x^{-}(\widetilde{\alpha})\right)^{2}=(B+\widetilde{\alpha}) x^{+}(\widetilde{\alpha})-\frac{1}{2}\left(x^{+}(\widetilde{\alpha})\right)^{2}
$$

It follows that

$$
\frac{1}{2}\left[\left(x^{+}(\widetilde{\alpha})\right)^{2}-\left(x^{-}(\widetilde{\alpha})\right)^{2}\right]=(B+\widetilde{\alpha})\left[x^{+}(\widetilde{\alpha})-x^{-}(\widetilde{\alpha})\right]
$$

From this equation, we deduce the following Property 2:

Property 2: At any point $\widetilde{a}$ where there is an upward jump discontinuity in the incentivecompatible schedule $x($.$) , it holds that$

$$
\widetilde{\alpha}=\frac{\left(x^{+}(\widetilde{\alpha})-B\right)+\left(x^{-}(\widetilde{\alpha})-B\right)}{2} .
$$

As a consequence of Property 1 and 2, we deduce Property 3:

Property 3: Under incentive compatibility, if a schedule $x($.$) has an upward jump of$ discontinuity at some $\widetilde{\alpha}$, it must hold that $x(\alpha)=x^{-}(\widetilde{\alpha})$ for all $\alpha \in\left(\alpha^{\prime}, \widetilde{\alpha}\right)$, and $x(\alpha)=$ $x^{+}(\widetilde{\alpha})$ for all $\alpha \in\left(\widetilde{\alpha}, \alpha^{\prime \prime}\right)$, where $\alpha^{\prime} \equiv x^{-}(\widetilde{\alpha})-B$ and $\alpha^{\prime \prime} \equiv x^{+}(\widetilde{\alpha})-B$. In other words, $a$ jump must be from one horizontal segment to another.

It follows from Properties 1, 2 and 3 that there are potentially four different types of incentive-compatible schedules:

(i) First, the "fully flexible schedule", $x(\alpha)=B+\alpha$ for all $\alpha \in[-\delta-\varepsilon, \delta+\varepsilon]$. That is, the politician is unconstrained in her choice of $x$. 
(ii) Second, "semi-flexible schedules": $x(\alpha)=B+\alpha$ for all $\alpha$ in some interval $\left[\alpha_{0}, \alpha_{1}\right]$, with a policy cap (i.e., $x-B$ is not permitted to exceed $\alpha_{1}<\varepsilon+\delta$ ), or a policy floor (i.e., $x-B$ is not permitted to be below the level $\alpha_{0}>-\varepsilon-\delta$ ), or both a cap and a floor.

(iii) Third, "step schedules": $x(\alpha)$ is a step function. There are possibly $n$ intervals, $\left[\alpha_{0}, \alpha_{1}\right),\left[\alpha_{1}, \alpha_{2}\right), \ldots,\left[\alpha_{n-1}, \alpha_{n}\right]$ and over each interval $i, x$ is a constant, $x_{i}$, where $x_{1}<x_{2}<$ $\ldots<x_{n}=x_{n}$.

(iv) Fourth, "hybrid schedules": a hybrid schedule may include several flexible segments, and several step-wise discontinuities.

Due to the incentive-compatibility constraint (11) and the presence of the double integral (10), the solution of Problem 1 is not straightforward. We must proceed using a number of steps before reaching our main results.

Before solving Problem 1, in order to aid our intuition, it will be instructive to consider two simpler scenarios, which also serve as useful benchmarks for comparison with our main results.

\section{Two benchmark scenarios}

Before analyzing in full our more general model, we consider two benchmark cases. In the first benchmark, we assume that the median voter, not knowing the direction and magnitude of bias in the politician's preference, must choose one of the following alternatives: (i) giving the elected politician the full freedom to choose policy, versus (ii) requiring that policy must be decided by voters (who are uninformed about the state of the world). We show that in this case, as long as the median voter's uncertainty about the politician's bias is less than the uncertainty about the state of the world, the median voter's expected utility is higher under (i) than under (ii). In our second benchmark scenario, we assume that the politician's bias is known. In this case we obtain results which are in line with Amador and Bagwell (2013): the principal sets a policy cap when the politician is known to have a rightist bias, and a policy floor is set when the politician is known to have a leftist bias. 


\subsection{The first benchmark: choice between unfettered representa- tive democracy and direct democracy}

In the first benchmark case, we assume that the median voter, while facing uncertainty about both $\theta$ and $t$, is restricted to making a choice between: (a) "Unfettered representative democracy," namely letting the politician choose any action $x$ she wants, and (b) "Direct democracy," i.e., the voters, though uninformed, decide on the policy level $x$ by voting.

Under unfettered representative democracy, the elected politician, having observed $\theta+t$, is free to choose any $x$. She will then choose the policy level that maximizes her own selfinterest, i.e., $x(\theta+t)=B+\theta+t$. In this case, the median voter's resulting expected utility can be computed as follows:

$$
\int_{-\delta}^{\delta}\left\{\int_{-\varepsilon}^{\varepsilon}\left[(B+\theta)(B+\theta+t)-\frac{1}{2}(B+\theta+t)^{2}\right] \frac{1}{2 \varepsilon} d \theta\right\} \frac{1}{d \delta} d t=\frac{1}{2} B^{2}+\frac{1}{6}\left(\varepsilon^{2}-\delta^{2}\right)
$$

Under direct democracy, the decision on $x$ is made by the voters. Since they do not observe $\theta$, the median voter will choose $x$ to maximize $B x-\frac{1}{2} x^{2}$, resulting in the "constant policy", i.e. $x=B$ always. His expected utility is $\frac{1}{2} B^{2}$.

Thus we have obtained the following result for our first benchmark scenario:

Result 1 (choice between unfettered representative democracy and direct democracy) Unfettered representative democracy would give rise to a higher welfare level to the median voter, as compared with direct democracy, if and only if $\delta<\varepsilon$ (i.e., iff the uncertainty about the politician's type is smaller than the uncertainty about the state of the world, $\theta)$.

In choosing between unfettered representative democracy (with an informed, but possibly biased politician) and uninformed direct democracy, the median voter faces the trade-off between, on one hand, the benefits of relying on a politician who has access to information about $\theta$, and on the other hand, the costs of (i) letting the politician set an $x$ that may exceed the upper bound on what the median voter would ever want, $B+\varepsilon$ (as the politician may have a rightist bias, and may choose $x>B+\varepsilon$ ), and (ii) letting the politician set an $x$ that falls below what the median voter would ever want (as the politician may have a leftist 
bias). If $\delta<\varepsilon$, these costs are not too large relative to the benefits, and therefore unfettered representative democracy is superior to direct democracy.

Remark 1: In considering the first benchmark scenario, we have assumed that the expected value of $t$ is zero, i.e., on average, the politician's bias is zero. It is easy to consider the modified assumption that $t$ is uniformly distributed over some interval $[-\delta+\mu, \delta+\mu]$, where $\mu \neq 0$. Then the expected value of the politician bias is $\mu$. In that case, under the assumption that $\delta<\varepsilon$, it can be shown that direct democracy is better than unfettered representative democracy if and only if the politician's bias is expected to be sufficiently large, in the sense that $3 \mu^{2}>\left(\varepsilon^{2}-\delta^{2}\right)$.

\subsection{The second benchmark scenario: the politician's bias is known}

We now turn to the second benchmark scenario. Here, we assume that the bias $t$ is known, but it is not too large. Specifically, we suppose that $-\varepsilon<t<\varepsilon$. This assumption rules out (i) the existence of a politician with a right-wing bias $t>\varepsilon$; such a politician would choose an action $x>B+\varepsilon$ if $\theta>0$, while the median voter would never want $x>B+\varepsilon$, whatever the realization of $\theta \in[-\varepsilon, \varepsilon]$, and (ii) the existence of a politician with a left-wing bias $t<-\varepsilon$.

Under this benchmark scenario, the optimal delegation in our model is simply a special case of a more general model of delegation under a known bias, which has been considered in Amador and Bagwell (2013). Since the distribution of $\theta$ is uniform over $[-\varepsilon, \varepsilon]$, it follows that, given that $t$ is a known constant, the distribution of $\alpha$ is uniform over $[-\varepsilon+t, \varepsilon+t]$. With

only one source of randomness, the solution of Problem 1 can be characterized relatively easily. We can prove the following results, for the case of a rightist bias, i.e., $t>0$. (A symmetric argument applies for the case of a leftist bias.)

Result 2: Given a known rightist bias $t>0$, the optimal incentive-compatible schedule has the properties that: (i) for all $\alpha<\varepsilon-t$, the politician is given the freedom to choose her self-interest-maximizing choice, namely, $x(\alpha)=\alpha+B$, and (ii) for all $\alpha \geq \varepsilon-t$ (i.e., for 
all $\theta \geq \varepsilon-2 t), x(\alpha)$ must be equal to the cap value, $B+\varepsilon-t$.

Similarly, given a known leftist bias $t<0$, the optimal incentive-compatible schedule has the properties that (i) for all $\alpha>-\varepsilon-t$, the politician is given the freedom to choose her self-interest-maximizing choice, and (ii) for all $\alpha \leq-\varepsilon-t$ (i.e., $\theta<-\varepsilon-2 t$ ), $x(\alpha)$ must equal the floor value $B-\varepsilon-t$ (which is greater than $B-\varepsilon$, since $t$ is negative).

The intuition behind Result 2 is straightforward. In the case of a known rightist bias, imposing a policy cap serves to rule out extreme-right policies. The greater the bias, the lower is the optimal cap. Notice that if the median voter were fully informed of the realization of state of the world $\theta$, she would want to set $x=B+\varepsilon$ in the event that $\theta$ takes its highest value, $\varepsilon$. Since she is actually uninformed, she wants to prevent the politician to set unduly high values of $x$, and thus she caps $x$ at $B+\varepsilon-t$, which is strictly below the maximum $x$ that she would choose under perfect information.

Similarly, in the case of a known leftist bias, imposing a policy floor rules out extreme left policies. The greater the bias, the higher is the floor. Notice that the floor is strictly higher than the lowest $x$ that the median voter would conceivably set under perfect information.

Remark 2: Result 2 above may be generalized to the case where the distribution of $\theta$ is not necessarily uniform. Assume simply a strictly positive continuous density function $f(\theta)$ over the set $[-\varepsilon, \varepsilon]$. It may be shown, using the approach of Amador and Bagwell (2013), that if $F(\theta)+t f(\theta)$ is non-decreasing, ${ }^{12}$ then:

(a) In the case of a known rightist bias $t>0$, the optimal schedule consists of (i) a flexible policy $x(\alpha)=\alpha+B$ for all $\alpha<y$ (i.e., all $\theta \leq y-t$ ), and (ii) for all $\alpha \geq y$ (i.e., all $\theta \geq y-t), x(\alpha)$ must equal the cap $y+B$, where $y$ is the solution of the following equation ${ }^{13}$

$$
\int_{y-t}^{\varepsilon}(\theta-y) f(\theta) d \theta=0 .
$$

(b) In the case of a known leftist bias $t<0$, the optimal schedule consists of (i) a flexible policy $x(\alpha)=\alpha+B$ for all $\theta \geq z-t$, (ii) for all $\theta \leq z-t, x(\alpha)$ must equal the floor value

\footnotetext{
${ }^{12}$ This is the condition ( $\left.c 1\right)$, of Amador and Bagwell (2013, p. 1550). An alternative and simpler proof is possible, along the lines of Laussel and Resende (2018).

${ }^{13}$ For the uniform distribution, we can see that $y=\varepsilon-t$.
} 
$z+B$, where $z$ is the solution of the following equation

$$
\int_{-\varepsilon}^{z-t}(\theta-z) f(\theta) d \theta=0
$$

\section{Optimal cap and floor: The case where the politi- cian's bias is private information}

We now solve for the optimal schedule $x(\alpha)$ when voters do not know the politician's bias, $t$. We assume that the variance of the distribution of $t$ is smaller than the variance of the distribution of the state of the world, $\theta$, i.e., we assume $\delta<\varepsilon$.

Proposition 1: It is optimal for the median voter to set both a policy cap and a policy floor, and to delegate the policy choice to the politician only for intermediate values of $\alpha$.

The cap is $\bar{x}=B+\varepsilon-\frac{\delta}{2}$, which applies for all $\alpha$ in the interval $\left[\varepsilon-\frac{\delta}{2}, \varepsilon+\delta\right]$. The floor is $x(\alpha)=B-\varepsilon+\frac{\delta}{2}$, which applies for all $\alpha$ in the interval $\left[-\varepsilon-\delta,-\varepsilon+\frac{\delta}{2}\right]$. And, for all $\alpha \in\left[-\varepsilon+\frac{\delta}{2}, \varepsilon-\frac{\delta}{2}\right]$, the politician is free to choose her $x$, and her choice is $x(\alpha)=\alpha+B$. The length of this delegation interval is $2 \varepsilon-\delta>0$.

\section{Corollary 1: (The state-uncertainty principle)}

The greater is the uncertainty about the state of the world, the wider is the delegation interval.

\section{Corollary 2: (The bias-uncertainty principle)}

The greater is the uncertainty about political bias, the smaller is the delegation interval.

Before proving Proposition 1, it is useful to state the following Lemma:

Lemma 1: For any incentive-compatible schedule $x($.$) , the median voter's expected$ utility is given by

$$
W^{M}=W^{A}(\underline{\alpha})+\int_{-\varepsilon-\delta}^{\varepsilon+\delta} x(\alpha)[\Theta(\alpha)-(B+\alpha)+h(\alpha)] f(\alpha) d \alpha
$$

or, equivalently, by

$$
W^{M}=W^{A}(\bar{\alpha})+\int_{-\varepsilon-\delta}^{\varepsilon+\delta} x(\alpha)[\Theta(\alpha)-(B+\alpha)-\phi(\alpha)] f(\alpha) d \alpha
$$


where $\underline{\alpha}=-\varepsilon-\delta, \bar{\alpha}=\varepsilon+\delta$, and where

(i) $\Theta(\alpha)$ is the expected value of $\theta+B$ conditional on the sum $\theta+t$ being equal to $\alpha$, where $t \in[-\delta, \delta]$. It is given by

$$
\Theta(\alpha) \equiv \frac{1}{f(\alpha)} \int_{D(\alpha)} \frac{(\theta+B)}{4 \delta \varepsilon} d \theta
$$

(ii) $h(\alpha) \equiv[1-F(\alpha)] / f(\alpha)$, and $\phi(\alpha) \equiv F(\alpha) / f(\alpha)$ where $f(\alpha)$ and $F(\alpha)$ are given by equations (5) and (6). Note that $h(\alpha)$ is the inverse of the hazard rate.

Proofs of Lemma 1 and Proposition 1: See the Appendix.

According to Proposition 1, the length of the delegation interval (over which the policy choice is fully delegated to a politician) is $\left[-\varepsilon+\frac{\delta}{2}, \varepsilon-\frac{\delta}{2}\right]$. This length is shrinks when the political uncertainty increases. Full delegation, i.e. unfettered representative democracy, is optimal if and only if there is no political uncertainty at all $(\delta=0)$. The optimal policy is pictured in Figure 1, where we set $B=0, \varepsilon=2$ and $\delta=1$. The cap $x(\alpha)=1.5$ applies for $\alpha \in[1.5,3]$ and the floor $x(\alpha)=-1.5$ applies for $\alpha \in[-3,-1.5]$. The flexible policy $x(\alpha)=\alpha$ is preferred when $\alpha \in[-1.5,1.5]$. The dashed line indicates what would be a flexible policy outside the range in which it is optimal.

\section{Discussion}

In this section, we discuss in more detail several issues that are neglected in our formal model.

First, in our model, we assumed that the incumbent is free from re-election concerns. The empirical evidence about the impact of re-election concerns on policy actions is mixed. On the one hand, there is some evidence that politicians often can afford to "shirk" (Kalt and Zupan, 1990; Matsusaka, 2004). According to Matsusaka (p. 598), "The limited information that constituents have about their representatives gives rise to the possibility of legislator shirking: representatives may be able to implement policies contrary to constituent interests without fear of being punished at the polls." Kalt and Zupan (1990, p. 106) reported empirical 
support for the hypothesis that the ideology manifested by policy makers represent rational shirking. On the other hand, there is also some evidence that politicians respond more to constituency if they face the prospect of re-election contests. For example, Christensen and Ejdemir (2017) found that elections in U.S. cities tend to improve municipal services, but they also create cycles in constituency responsiveness. Reviewing empirical tests of the predictions of political economy models of election, Christensen and Ejdemir (2017, p. 2) reported that "these models have been refuted almost as many times as they have been supported." 14

Second, we did not take account of the process of interpreting what the constitution says. Reviewing the roles of constitutional courts in European countries, Stone Sweet (2007, p. 87) states that "when a court declares a bill or statute unscontitutional, it vetoes the bill. Important legislatios vetoed by constitutional courts include the liberalization of abortion in Germany $(1975,1992)$ and Spain (1985), the nationalization of industry and financial institution in France (1981), the reform of German university governance (1973), the bid to introduce affirmative action in France (1982)." In the case of the USA, Vladeck (2010, pp. 297-8) lays out the various ways in which "the Constitution, as interpreted by the Supreme Court, imposes limits on the offender jurisdiction of court-martial." He documented a handful of cases in which "the Supreme Court has had the opportunity to expound on the constitutional limits of military commissions."

The constitution of Japan, though imposed by the USA after Japan's defeat in the Second World War, might be considered as reflecting Japan's median voter's preference since this document has not been amended over six decades. While the Japanese government is expected to maintain a self-defense force, Chapter 2 of Article 9 of Japan's constitution puts restriction on military capability: "Land, sea, air forces, as well as other war potential, will never be maintained. The right of belligerency of the state will not be recognized." Japan Self-Defence Forces (JSDF) may support military forces of other states only if such support

\footnotetext{
${ }^{14}$ See Brennan and Buchanan (1984) for further discussion.
} 
is restricted to logistic support; combatting roles to support military forces of other states are not permitted. These provisions imply a floor and a ceiling on military activities.

Our model on constraining future decision makers due to the uncertainty about their preference type has other applications. One example is the upper and lower limits on the withdrawals from one's old-age pension account that a pensioner is entitled to make each year (e.g., the case of Canada). These limits are prescribed by a government, which may be thought of as acting on behalf of the hypothetical non-biased self who worries about the potential bias of, say, their seventy-years-old future-selves, who might have an incentive to over-spend or under-spend, at the expense, or to the excessive benefit, of their eightyyears-old future selves. Another example is the rules that period-1 contracting parties to a free-trade agreement may impose on period-2 governments of the signatory countries. In fact, members of the World Trade Organization (WTO) agree to set a (country-specific) upper bound on the tariff rates (for various product categories) that they might impose in the future. A bound tariff rate on a product category is an upper bound in the tariff rate at which a WTO member applies to other WTO members. The gap between the bound rate and the applied rate is called the binding overhang. At present, the average bound tariff rate imposed by WTO members is around $10 \%$ while the average applied tariff rate is less than 4\%. Analyses of this type of problems were provided in Bagwell and Staiger (2005) and Amador and Bagwell (2013).

Finally, it is important to note that our model could be extended to allow for "money burning" in the sense that a constitution may permit a future politician to take certain extraordinary actions, but only at a cost to both the politician and the median voter (i.e., to both the agent and the principal). Money burning provisions can also apply to non-political contexts. For example, the provisions of a Christmas Club Saving Scheme would penalize a holder of a Christmas Club Saving Account who withdraws her savings much earlier than the planned withdrawal at Christmas time. (The model of Alonso and Matouschek (2008) allows money burning along these lines.) The development of a model that allows for money 
burning in the context of constitutional democracy is left for future research.

\section{Conclusion}

In this paper we have analyzed a delegation game between the median voter (the writer of the constitution) and the elected representative (the incumbent politician) in which the latter is privately informed of the state of the world and the former is uninformed about both the state of the world and the politician's type. The politician's type is seen as the exogenous random outcome of an electoral process which is not analyzed here. Our game may be considered to take place before the politician is elected, for instance when the constitution or, more generally the fundamental laws, are written. The main result is that, in that setting, it is optimal for the writer of the constitution, presumably the median voter, to impose an upper and a lower bound to the policies which the incumbent politician is allowed to implement, i.e., to tie the hands of future politicians.

This "interval delegation" result was already obtained in delegation models with known agent's type but is new in a model where the politician's type is private information. Moreover, the form taken here by the interval delegation, with an upper and a lower limit, is itself new compared with the results obtained in applied delegation models with known agent's type. Most papers on interval delegation specialize their results to the case where the agent's bias is not affected by the state of the world. In contrast, in our model, where not only the state of the world but also the agent's type are private information, we prove that policy restrictions take the form of a delegation interval between a floor and a cap.

We are rather confident that these results would extend to the case of more general distribution functions. More specifically, we conjecture that three natural assumptions may be sufficient to entail the optimality of an interval delegation with a cap and a floor: (i) a nonincreasing hazard rate, $h^{\prime}(\alpha) \leq 0$, (ii) a derivative $\Theta^{\prime}(\alpha) \leq 1$ and (iii) a symmetric density function $f(\alpha)$ that is non-decreasing between $-\varepsilon-\delta$ and 0 and non-increasing between 0 and $\varepsilon+\delta$. Obviously, these conditions are satisfied when the distributions of $\theta$ and $t$ are 
uniform as assumed here. We hope to establish a proof of this more general result in a future technical note.

Are our results likely to be substantially changed when the incumbent must periodically run for reelection? Clearly not if politicians are primarily policy-motivated: a pure screening effect of reelection would reduce but would not remove ex ante political uncertainty. In the opposite polar case, if the incumbent first and foremost wants to be reelected, the writer of the constitution has to explicitly account for this constraint in the incumbent's program. This is part of our research agenda.

Finally, it would certainly be interesting to consider the case where the political process is not only random but also biased, i.e. when the writer of the constitution rationally expects the politician's preference to differ from that of the median voter for a variety of reasons. It is very likely that the symmetry between the floor and the cap would be lost: the writer of the constitution would want impose stronger constraints on the hands of future politicians in the direction in which they are more likely to be biased. 


\section{Appendix}

\section{Proof of Result 2}

The proof is given for the case of a rightist bias $(t>0)$. A similar argument applies in the case of a leftist bias. The proof proceeds in three steps.

Step 1: With a known bias $t$, it is never optimal for the median voter to set a discontinuous schedule $x(\alpha)-B$ involving a step function over an interval $\left[\alpha_{0}, \alpha_{1}\right] \subset[-\varepsilon+t, \varepsilon-t]$.

Proof: In view of Facts 1, 2 and 3, without loss of generality, consider a schedule $x(\alpha)-B$ that has a discontinuity at point $\widetilde{\alpha}=\left(\alpha_{0}+\alpha_{1}\right) / 2$, with $x^{-}(\widetilde{\alpha})-B=\alpha_{0}$ and $x^{+}(\widetilde{\alpha})-B=\alpha_{1}$. Then $x(\alpha)-B=\alpha_{0}$ for all $\alpha \in\left[\alpha_{0}, \widetilde{\alpha}\right)$ and $x(\alpha)-B=\alpha_{1}$ for all $\alpha \in\left[\widetilde{\alpha}, \alpha_{1}\right]$. We now show that we can construct an alternative schedule $x^{\#}(\alpha)-B$ that dominates $x(\alpha)-B$. Let $x^{\#}(\alpha)-B=x(\alpha)-B$ for all $\alpha$ outside $\left[\alpha_{0}, \alpha_{1}\right]$, and $x^{\#}(\alpha)-B=\alpha$ for all $\alpha \in\left[\alpha_{0}, \alpha_{1}\right]$. Then the median voter's expected utility under schedule $x^{\#}(\alpha)-B$ exceeds his expected utility under $x(\alpha)-B$ by the amount $\Delta$ given below:

$\Delta \equiv \frac{1}{2 \varepsilon} \int_{\alpha_{0}}^{\alpha_{1}}\left((\alpha-t) \alpha-\frac{1}{2} \alpha^{2}\right) d \alpha-\frac{1}{2 \varepsilon} \int_{\alpha_{0}}^{\widetilde{\alpha}}\left((\alpha-t) \alpha_{0}-\frac{1}{2} \alpha_{0}^{2}\right) d \alpha-\frac{1}{2 \varepsilon} \int_{\widetilde{\alpha}}^{\alpha_{1}}\left((\alpha-t) \alpha_{1}-\frac{1}{2} \alpha_{1}^{2}\right) d \alpha$

Write

$$
x=\alpha_{0}, u=\widetilde{\alpha}=\frac{x+y}{2}, y=\alpha_{1}>x
$$

The terms that have $t$ as a multiplicative factor cancel each other out. The remaining terms are

$$
\frac{1}{2 \varepsilon} \int_{x}^{u}\left(\frac{1}{2} \alpha^{2}+\frac{1}{2} x^{2}-\alpha x\right) d \alpha+\frac{1}{2 \varepsilon} \int_{u}^{y}\left(\frac{1}{2} \alpha^{2}+\frac{1}{2} y^{2}-\alpha y\right) d \alpha=\frac{1}{48 \varepsilon}(y-x)^{3}>0
$$

Step 2: If $t>0$, any schedule $x(\alpha)-B$ with a floor, i.e., $x(\alpha)-B=\alpha_{0}$ for all $\alpha \in\left[-\varepsilon+t, \alpha_{0}\right]$ is not optimal.

Proof: Consider an alternative schedule $x^{\#}(\alpha)$ which is identical to $x(\alpha)$ outside the interval $\left[-\varepsilon+t, \alpha_{0}\right]$, and $x^{\#}(\alpha)-B=\alpha$ for all $\alpha$ in the interval $\left[-\varepsilon+t, \alpha_{0}\right]$.

The excess of the median voter's expected utility under $x^{\#}($.$) over his expected utility$ 
under $x($.$) is$

$$
\Delta=\frac{1}{2 \varepsilon} \int_{-\varepsilon+t}^{\alpha_{0}}\left((\alpha-t) \alpha-\frac{1}{2} \alpha^{2}\right) d \alpha-\frac{1}{2 \varepsilon} \int_{-\varepsilon+t}^{\alpha_{0}}\left((\alpha-t) \alpha_{0}-\frac{1}{2} \alpha_{0}^{2}\right) d \alpha
$$

Let $x=-\varepsilon+t$ and $y=\alpha_{0}>-\varepsilon+t$. Then

$$
\begin{gathered}
\int_{x}^{y}\left((\alpha-t) \alpha-\frac{1}{2} \alpha^{2}\right) d \alpha=-t\left(\frac{y^{2}}{2}-\frac{x^{2}}{2}\right)+\left(\frac{y^{3}}{6}-\frac{x^{3}}{6}\right) \\
\int_{x}^{y}\left((\alpha-t) y-\frac{1}{2} y^{2}\right) d \alpha=y\left(\frac{y^{2}}{2}-\frac{x^{2}}{2}\right)-y t(y-x)-\frac{y^{2}}{2}(y-x)
\end{gathered}
$$

Thus

$$
\begin{aligned}
2 \varepsilon \Delta & =-t\left(\frac{y^{2}}{2}-\frac{x^{2}}{2}\right)+\left(\frac{y^{3}}{6}-\frac{x^{3}}{6}\right)-\left(y\left(\frac{y^{2}}{2}-\frac{x^{2}}{2}\right)-y t(y-x)-\frac{y^{2}}{2}(y-x)\right) \\
& =\frac{1}{6}(y-x)^{2}(3 t-x+y) \\
& =\frac{1}{6}\left(\alpha_{0}+\varepsilon-t\right)^{2}\left(2 t+\varepsilon+\alpha_{0}\right)>0 \text { if } t>0 .
\end{aligned}
$$

Step 3: From Step 1 and Step 2, the only remaining possibilities are (i) a fully flexible schedule, and (ii) a semi-flexible schedule with a cap that applies for all $\alpha \in\left[\alpha_{1}, \varepsilon+t\right]$, for some $\alpha_{1} \leq \varepsilon+t$. Note that a fully flexible policy is equivalent to a semi-flexible policy, with a cap that applies only at $\alpha_{1}=\varepsilon+t$. Therefore, to prove Result 2 , it suffices to show that the optimal cap must be operative for all $\alpha \geq \varepsilon-t$, and at $\alpha=\varepsilon-t, x(\varepsilon-t)=\varepsilon-t$.

To prove this, we compute the median voter's expected utility under a semi-flexible policy and show that it attains its maximum at $\alpha_{1}=\varepsilon-t$. The median voter's expected utility is computed as follows. Let $x=B-\varepsilon+t$ and $v=B+\varepsilon+t$. Let $y=\alpha_{1}$. Then the median voter seeks to maximize the sum of following integrals, by choosing $y$

$$
\int_{x}^{y}\left((B+\alpha-t)(B+\alpha)-\frac{1}{2}(B+\alpha)^{2}\right) d \alpha+\int_{y}^{v}\left((B+\alpha-t)(B+y)-\frac{1}{2}(B+y)^{2}\right) d \alpha
$$

Differentiating the above integrals with respect to $y$, using Leibnitz's rule, we obtain the first order condition for a maximum:

$$
-\frac{1}{2}(v-y)(2 t-v+y)=0
$$


The solution $y=v-2 t$ satisfies both the FOC and SOC.

\section{Proof of Lemma 1}

From (13) and (16), and defining $\underline{\alpha}=-\varepsilon-\delta$ and $\bar{\alpha}=\varepsilon+\delta$

$$
\begin{aligned}
-\frac{x(\alpha)^{2}}{2} & =-(B+\alpha) x(\alpha)+W^{A}(\alpha)=-(B+\alpha) x(\alpha)+W^{A}(\underline{\alpha})+\int_{\underline{\alpha}}^{\alpha} x\left(\alpha^{\prime}\right) d \alpha^{\prime} \\
& \equiv-(B+\alpha) x(\alpha)+W^{A}(\underline{\alpha})+K(\alpha)
\end{aligned}
$$

with $K^{\prime}(\alpha) \equiv x(\alpha)$. Then

$$
-\int_{\underline{\alpha}}^{\bar{\alpha}} \frac{1}{2} x(\alpha)^{2} f(\alpha) d \alpha=W^{A}(\underline{\alpha})-\int_{\underline{\alpha}}^{\bar{\alpha}}(B+\alpha) x(\alpha) f(\alpha) d \alpha+\int_{\underline{\alpha}}^{\bar{\alpha}} K(\alpha) f(\alpha) d \alpha
$$

Integrating $K(\alpha) f(\alpha)$ by parts gives

$$
\begin{aligned}
\int_{\underline{\alpha}}^{\bar{\alpha}} K(\alpha) f(\alpha) d \alpha & =[K(\bar{\alpha}) F(\bar{\alpha})-K(\underline{\alpha}) F(\underline{\alpha})]-\int_{\underline{\alpha}}^{\bar{\alpha}} x(\alpha) F(\alpha) d \alpha \\
& =\int_{\underline{\alpha}}^{\bar{\alpha}} x(\alpha) d \alpha-\int_{\underline{\alpha}}^{\bar{\alpha}} x(\alpha) F(\alpha) d \alpha=\int_{\underline{\alpha}}^{\bar{\alpha}} x(\alpha)\left[\frac{1-F(\alpha)}{f(\alpha)}\right] f(\alpha) d \alpha \\
& \equiv \int_{\underline{\alpha}}^{\bar{\alpha}} x(\alpha) h(\alpha) f(\alpha) d \alpha
\end{aligned}
$$

Then

$$
-\int_{\underline{\alpha}}^{\bar{\alpha}} \frac{1}{2} x(\alpha)^{2} f(\alpha) d \alpha=W^{A}(\underline{\alpha})+\int_{\underline{\alpha}}^{\bar{\alpha}} x(\alpha)[h(\alpha)-(B+\alpha)] f(\alpha) d \alpha
$$

Using (8), (9), (10) and (A.1), the expected utility of the median voter can be written as

$$
W^{M}=\int_{\underline{\alpha}}^{\bar{\alpha}} x(a)[\Theta(\alpha)+h(\alpha)-(B+\alpha)] f(\alpha) d \alpha+W^{A}(\underline{\alpha})
$$

where

$$
\Theta(\alpha) \equiv \frac{1}{f(\alpha)} \int_{D(\alpha)} \frac{(B+\theta)}{4 \delta \varepsilon} d \theta .
$$

This establishes (20). A similar argument establishes (21). As a verification, note that if we subtract equation (21) from (20), we get

$$
0=W(\underline{\alpha})-W(\bar{\alpha})+\int_{-\varepsilon-\delta}^{\varepsilon+\delta} x(\alpha) d \alpha=W(\underline{\alpha})-W(\bar{\alpha})+\int_{-\varepsilon-\delta}^{\varepsilon+\delta} \frac{d W}{d \alpha} d \alpha
$$

which is correct. 


\section{Proof of Proposition 1}

The proof consists of three steps. The first is to show that a flexible policy is always better than any discontinuous incentive-compatible policy when $\alpha \in\left[-\varepsilon-\frac{\delta}{2}, \varepsilon+\frac{\delta}{2},\right]$. The second one is to prove that (i) it is better to have some policy cap (resp. policy floor) and that (ii) the optimal policy cap (resp. policy floor) is such that $x(\alpha)-B=\varepsilon-\frac{\delta}{2}$ for all $\alpha \in\left[\varepsilon-\frac{\delta}{2}, \varepsilon+\delta\right]$ (resp. such that $x(\alpha)-B=-\varepsilon+\frac{\delta}{2}$ for all $\alpha \in\left[-\varepsilon-\delta,-\varepsilon+\frac{\delta}{2}\right]$ ). Then, in step 3, we prove that discontinuous policies are also dominated at the two extremes of the interval.

Step 1: Consider any incentive-compatible schedule $x(\alpha)-B$ that has a jump discontinuity at some $\widetilde{\alpha}$, where $\widetilde{\alpha}=\frac{\alpha_{0}+\alpha_{1}}{2}$ and $-\varepsilon+\frac{\delta}{2}<\alpha_{0}<\alpha_{1}<\varepsilon-\frac{\delta}{2}$. We will show that such a schedule is dominated by a similar schedule that does not have a jump. In fact, let $x^{-}(\widetilde{\alpha})-B=\alpha_{0}$ and $x^{+}(\widetilde{\alpha})-B=\alpha_{1}$. Then $x(\alpha)-B=\alpha_{0}$ for all $\alpha \in\left[\alpha_{0}, \widetilde{\alpha}\right)$ and $x(\alpha)-B=\alpha_{1}$ for all $\alpha \in\left[\widetilde{\alpha}, \alpha_{1}\right]$. We now show that we can construct an alternative schedule $x^{\#}(\alpha)-B$ that dominates $x(\alpha)-B$. Let $x^{\#}(\alpha)-B$ be the same as $x(\alpha)-B$ except over the interval $\left[\alpha_{0}, \alpha_{1}\right]$, where $x^{\#}(\alpha)-B=\alpha$. Note that $x(\alpha)-B$ is a step function over the interval $\left[\alpha_{0}, \alpha_{1}\right]$ and the discontinuity occurs at $\widetilde{\alpha}=\left(\alpha_{0}+\alpha_{1}\right) / 2$, with

$$
B+\alpha_{0}=\lim _{\alpha \uparrow \widetilde{\alpha}} x(\alpha) \equiv x^{-}(\widetilde{\alpha})<x^{+}(\widetilde{\alpha}) \equiv \lim _{\alpha \downarrow \widetilde{\alpha}} x(\alpha)=B+\alpha_{1}>B+\widetilde{\alpha}
$$

We must show that the excess of the median voter's expected utility under the schedule $x^{\#}()-$.$B over his expected utility under the schedule x()-$.$B is strictly positive. Using$ (20), and defining $g(\alpha)=[\Theta(\alpha)-(B+\alpha)+h(\alpha)] f(\alpha)$, this excess is given

$$
\begin{aligned}
\Delta\left(\alpha_{0}, \alpha_{1}\right) & =\int_{\alpha_{0}}^{\alpha_{1}} \alpha g(\alpha) d \alpha-\left\{\int_{\alpha_{0}}^{\widetilde{\alpha}} \alpha_{0} g(\alpha) d \alpha+\int_{\widetilde{\alpha}}^{\alpha_{1}} \alpha_{1} g(\alpha) d \alpha\right\} \\
& =\int_{\alpha_{0}}^{\alpha_{1}} \alpha g(\alpha) d \alpha-\left\{\alpha_{1}\left[G\left(\alpha_{1}\right)-G(\widetilde{\alpha})\right]+\alpha_{0}\left[G(\widetilde{\alpha})-G\left(\alpha_{0}\right)\right]\right\}
\end{aligned}
$$

where

$$
G(\alpha) \equiv \int_{\alpha}^{\varepsilon+\delta} g(\alpha) d \alpha
$$

Notice that $\Delta\left(\alpha_{0}, \alpha_{0}\right)=0$. Thus, if we can show that $\partial \Delta\left(\alpha_{0}, \alpha_{1}\right) / \partial \alpha_{1}>0$ then we can 
conclude that $\Delta\left(\alpha_{0}, \alpha_{1}\right)>0$ or all $\alpha_{1}>\alpha_{0}$. To show that $\partial \Delta\left(\alpha_{0}, \alpha_{1}\right) / \partial \alpha_{1}>0$, note that

$$
\partial \Delta\left(\alpha_{0}, \alpha_{1}\right) / \partial \alpha_{1}=G(\widetilde{\alpha})-G\left(\alpha_{1}\right)+g(\widetilde{\alpha})\left(\alpha_{1}-\widetilde{\alpha}\right)
$$

If $g^{\prime}(\alpha)<0$ (which implies that $G($.$) is a strictly concave function), then clearly the RHS of$ (A.2) is indeed strictly positive,. We now prove that $g^{\prime}(\alpha)<0$. Recall that by definition,

$$
g(\alpha) \equiv[1-F(\alpha)]-(B+\alpha) f(\alpha)+\int_{D(\alpha)} \frac{(\theta+B)}{4 \delta \varepsilon} d \theta
$$

and $f(\alpha)$ and $F(\alpha)$ are given by (5) and (6). Then direct computation shows that

$$
g(\alpha)=\left\{\begin{array}{c}
-\frac{\alpha^{2}+\alpha(\delta+2 \varepsilon)-3 \delta \varepsilon+\varepsilon^{2}}{4 \varepsilon \delta}, \forall \alpha \in[-\varepsilon-\delta, \delta-\varepsilon] \\
\frac{\varepsilon-\alpha}{2 \varepsilon}, \forall \alpha \in[\delta-\varepsilon, \varepsilon-\delta] \\
\frac{(\varepsilon-\alpha)(\varepsilon+\delta-\alpha)}{4 \varepsilon \delta}, \forall \alpha \in[\varepsilon-\delta, \varepsilon+\delta]
\end{array} .\right.
$$

It is easy to see that $g^{\prime}(\alpha)<0, \forall \alpha \in\left(-\varepsilon-\frac{\delta}{2}, \varepsilon+\frac{\delta}{2}\right)$.

Step 2: Having shown that it is not optimal to have a discontinuous schedule $x(\alpha)-B$, we now show that, among all the continuous semi-flexible schedules $x(\alpha)-B$, setting a policy cap is always optimal, and, moreover, the best policy cap is $x(\alpha)-B=\varepsilon-\frac{\delta}{2}$ for all $\alpha \in\left[\varepsilon-\frac{\delta}{2}, \varepsilon+\delta\right]$.

Let us consider an arbitrary incentive-compatible schedule $x(\alpha)$ with a policy cap $\bar{x}-B=$ $\alpha_{1}$ for some $\alpha_{1}$, i.e., $x(\alpha)-B=\alpha_{1}$ for all $\alpha \in\left[\alpha_{1}, \varepsilon+\delta\right]$. Using (20), we compute the difference between the median voter's expected utility obtained from this schedule, and his/her expected utility obtained from an alternative schedule $x^{\dagger}(\alpha)$ such that (i) $x^{\dagger}(\alpha)-B$ is identical to $x(\alpha)-B$ for all $\alpha \in\left[-\varepsilon-\delta, \alpha_{1}\right]$ and (ii) for all $\alpha \in\left[\alpha_{1}, \varepsilon+\delta\right]$ we have $x^{\dagger}(\alpha)-B=\alpha$ (i.e., it is flexible in this interval). The difference in expected utility levels obtained from $x(\alpha)$ and $x^{\dagger}(\alpha)$ is

$$
\Delta W\left(\alpha_{1}\right)=\int_{\alpha_{1}}^{\varepsilon+\delta}\left(\alpha_{1}-\alpha\right) g(\alpha) d \alpha
$$

where $g(\alpha)$ is given by (A.3). Direct computation shows that

$$
\Delta W\left(\alpha_{1}\right)=\left\{\begin{array}{c}
\frac{\delta^{2}-\varepsilon^{2}-3 \alpha_{1}^{2}}{6}-\frac{\left(\alpha+\delta+\alpha_{1}\right)^{3}\left(\delta-\varepsilon-\alpha_{1}\right)}{48 \delta \delta}<0, \text { if } \alpha \in[-\varepsilon-\delta, \delta-\varepsilon] \\
\frac{\left(\alpha_{1}-\varepsilon\right)\left(\alpha_{1}-\delta-\varepsilon\right)\left(\alpha_{1}+\delta-\varepsilon\right)}{12 \varepsilon} \leq 0, \text { if } \alpha_{1} \in[\delta-\varepsilon, \varepsilon-\delta] \\
\frac{1}{48 \delta \varepsilon}\left(\alpha_{1}+\delta-\varepsilon\right)\left(\delta+\varepsilon-\alpha_{1}\right)^{3}, \text { if } \alpha_{1} \in[\varepsilon-\delta, \varepsilon+\delta]
\end{array} .\right.
$$


Thus, $\Delta W\left(\alpha_{1}\right)$ is equal to 0 at the value $\alpha_{1}=\varepsilon+\delta$ and also at the value $\alpha_{1}=\varepsilon-\delta$, and it is strictly positive for all $\alpha_{1} \in(\varepsilon-\delta, \varepsilon+\delta)$ and strictly negative if $\alpha_{1}<\varepsilon-\delta$. In particular, $\Delta W\left(\alpha_{1}\right)$ attains its maximum value at $\alpha_{1}=\varepsilon-\frac{\delta}{2}$. It follows that the best policy cap is to set the cap $\bar{x}=B+\varepsilon-\frac{\delta}{2}$, that is, $x(\alpha)=B+\varepsilon-\frac{\delta}{2}$ for all $\alpha \in\left[\varepsilon-\frac{\delta}{2}, \varepsilon+\delta\right]$. With the optimal cap, we find that the endogenously determined $W^{A}(\bar{\alpha})$ is given by $W^{A}(\bar{\alpha})=$ $(B+\bar{\alpha})\left(B+\varepsilon-\frac{\delta}{2}\right)-\frac{1}{2}\left(B+\varepsilon-\frac{\delta}{2}\right)^{2}$.

Step 3: We now show that any schedule $x(\alpha)-B$ that has a discontinuous jump to a cap, where the discontinuity occurs at some $\widetilde{\alpha}$ in the interior of the interval $\left[\varepsilon-\frac{\delta}{2}, \varepsilon+\delta\right]$ with the cap being set such that $\bar{x}-B=\alpha_{1}$ where $\varepsilon+\delta \geq \alpha_{1}>\widetilde{\alpha}$ (i.e., $x(\alpha)-B=\alpha_{1}$ for all $\alpha \in(\widetilde{\alpha}, \varepsilon+\delta])$ is dominated by the schedule $x^{\#}(\alpha)-B$ which is identical to $x(\alpha)-B$ for all $\alpha \leq \alpha_{0}$ where $\frac{\alpha_{1}+\alpha_{0}}{2}=\widetilde{\alpha}$, and which has a cap $\bar{x}^{\#}-B=\alpha_{0}$, i.e. $x^{\#}(\alpha)-B=\alpha_{0}$ for all $\alpha \in\left[\alpha_{0}, \varepsilon+\delta\right]$.

Indeed the expected median voter's utility under $x^{\#}($.$) exceeds the one under x($.$) by$

$$
\begin{aligned}
\int_{\frac{\alpha_{0}+\alpha_{1}}{2}}^{\varepsilon+\delta}\left(\alpha_{0}-\alpha_{1}\right) g(\alpha) d \alpha & = \\
\frac{1}{96 \varepsilon \delta}\left(\alpha_{1}-\alpha_{0}\right)\left(\alpha_{0}+\alpha_{1}-2 \varepsilon+\delta\right)\left(\alpha_{1}+\alpha_{0}-2(\varepsilon+\delta)\right)^{2} & >0 .
\end{aligned}
$$

Remark: By an argument symmetrical to Step 2, a policy floor is always optimal. In fact, using equation (21) to compute the difference between the median voter's expected utility obtained from a schedule $x(\alpha)-B$ with a floor, and an alternative schedule $x^{\dagger}(\alpha)-B$ without a floor, we can show that the best policy floor is $x(\alpha)=B-\varepsilon+\frac{\delta}{2}$ for all $\alpha \in$ $\left[-\varepsilon-\delta,-\varepsilon+\frac{\delta}{2}\right]$. By an argument symmetrical to Step 3, one can show that any schedule with a discontinuity at some $\widetilde{\alpha}$ in the interior of the interval $\left[-\varepsilon-\delta,-\varepsilon+\frac{1}{2} \delta\right]$ is dominated by a continuous schedule. With the optimal floor, we find that the endogenously determined $W^{A}(\underline{\alpha})$ is given by $W^{A}(\underline{\alpha})=(B+\underline{\alpha})\left(B-\varepsilon+\frac{1}{2} \delta\right)-\frac{1}{2}\left(B-\varepsilon+\frac{1}{2} \delta\right)^{2}$.

Conclusion: Discontinuous equilibria are ruled out by Step 1 when $\widetilde{\alpha} \in\left(-\varepsilon-\frac{\delta}{2}, \varepsilon+\frac{\delta}{2}\right)$ and by Steps 3-4 when $\widetilde{\alpha}>\varepsilon-\frac{\delta}{2}$ or $\widetilde{\alpha}<-\varepsilon+\frac{\delta}{2}$. Since $\left[-\varepsilon+\frac{\delta}{2}, \varepsilon-\frac{\delta}{2}\right] \subset\left(-\varepsilon-\frac{\delta}{2}, \varepsilon+\frac{\delta}{2}\right)$, it 
follows that discontinuous incentive-compatible policies never maximize the median voter's expected utility. The only possible equilibria are then flexible or semi-flexible incentive compatible policies. From Steps 2 and 4, the best of them is the semi-flexible policy described in Proposition 1.

\section{References}

[1] Alonso, R. and N. Matouschek (2008). Optimal Delegation, The Review of Economic Studies 75(1), 259-293.

[2] Amador, M. and K. Bagwell (2012), Tariff Revenue and Tariff Caps, American Economic Review, Papers and Proceedings, 102, 459-465.

[3] Amador, M. and K. Bagwell (2013), The Theory of Optimal Delegation with an Application to Tariff Caps, Econometrica 81, 1541-1599.

[4] Amador, M., I. Werning and G-M Angeletos (2006). Commitment vs. Flexibility, Econometrica 74, 365-396.

[5] Ambrus, A. and G. Egorov (2009), Delegation and Non-Monetary Incentives, Working Paper, Harvard University.

[6] Armstrong, M. (1995), Delegating Decision-Making to an Agent with Unknown Preferences," mimeo, UCL. (A version of this paper is titled "Delegation and Discretion", 1995, and is available on line at http://mpra.ub.uni-muenchen.de/17069/)

[7] Ashworth, S. (2012), Electoral accountability: recent theoretical and empirical work. Annual Review of Political Science 15, 183-201.

[8] Banks, J. S., \& J. Duggan (2008), A dynamic model of democratic elections in multidimensional policy space. Quarterly Journal of Political Science 3, 269-99. 
[9] Bagwell, K. and R.W. Staiger (2005), Enforcement, Private Political Pressure and the General Agreement on Tariffs and Trade/World Trade Organization Escape Clause, Journal of Legal Studies 3, 471-513.

[10] Besley, T. (2006), Principled Agents, The Lindhal Lectures, Oxford University Press.

[11] Beshkar, M, E. Bond and Y. Rho (2011), Tariff Binding and Overhang: Theory and Evidence, Working Paper.

[12] Besley, T. and A. Case (1995), Incumbent Behavior: Vote Seeking, Tax Setting and Yardstick Competition, American Economic Review 85, 25-45.

[13] Besley, T. and S. Coate (1997), An Economic Model of Representative Democracy, Quarterly Journal of Economics 112, 85-114.

[14] Brennan, G. and J. Buchanan (1984). "Voter Choice: Evaluating Political Alternatives," American Behavioral Scientist 24, 185-201.

[15] Burke, E. (1854), The Works of the Right Honourable Edmund Burke. Volume I. London: Henry G. Bohn. 1854. pp. 446-8.

[16] Coate, S and S. Morris (1995), On the Form of Transfers to Special Interests, Journal of Political Economy 103, 1210-35.

[17] Constant, B. (1819), De la liberté des Anciens comparée à celle des Modernes,http://etienne.chouard. free.fr/Europe/Docs/Constant_Benjamin_Liberte_anciens_modernes_1819.pdf

[18] Christensen, D. and S. Ejdemyr (2017), Do Elections Improve Constituency Responsiveness? Evidence from U.S. Cities, mimeo, available at https://sejdemyr.github.io/docs/CE-20170824.pdf.

[19] Christiansen, N. (2013), Strategic Delegation in a Legislative Bargaining Model with Pork and Public Goods. Journal of Public Economics 97: 217-229. 
[20] Downs, A. (1957), An Economic Theory of Democracy. Haper Collins, New York, NY.

[21] Duggan, J., \&M. Feys (2006), Repeated Downsian Electoral Competition, International Journal of Game Theory 35(1), 39-69.

[22] Fearon, J. (1999), Electoral Accountability and the Control of Politicians: Selecting Good Types versus Sanctioning Poor Performance, in Adam Przeworski, Bernard Manin and Susan C. Stokes (eds.), Democracy, Accountability, and Representation. Cambridge University Press, pp. 55-97.

[23] Ferejohn, J. (1986), Incumbent Performance and Electoral Control, Public Choice 50(1), $5-25$.

[24] Fontana, B.-M. (1988), "The liberty of the ancients compared with that of the moderns," in B.M. Fontana (ed.), The Political Writings of Benjamin Constant. Cambridge University Press,

[25] Gilens, M. (2014), Affluence and Influence, Economic Inequality and Political Power in America, Princeton: Princeton University Press.

[26] Gilens, M. and B. Page (2018). Testing Theories of American Politics: Elites, Interest Groups, and Average Citizens." Perspectives on Politics (forthcoming).

[27] Großer, J. and T.R. Palfrey (2009), A citizen candidate model with private information, in The Political Economy of Democracy, ed. E. Aragonés, C. Beviá, H. Llavador, and N. Schofield, Bilbao, Spain: Fundación BBVA: 15-29.

[28] Großer, J. and T.R. Palfrey (2014), Candidate entry and political polarization: An antimedian voter theorem, American Journal of Political Science, 58, 127-43.

[29] Großer, J. and T.R. Palfrey (2017), Candidate entry and political polarization: An experimental study, available at SSRN: https://ssrn.com/abstract=2967635. 
[30] Hamilton, A., Madison, J., and Jay, J. (1788/1961). The Federalist Papers (with an introduction, table of contents, and index of ideas by C. Rossiter). New York: Mentor.

[31] Hillman, A. L. and N. V. Long (2018), Policies and Prizes. European Journal of Political Economy, 54 (C): 99-109.

[32] Holmström, B. (1977), "On Incentives and Control in Organizations," Ph.D. thesis, Stanford University.

[33] Holmström, B. (1984), "On the Theory of Delegation," in M. Boyer, and R. Kihlstrom (eds.), Bayesian Models in Economic Theory, North-Holland, Amsterdam.

[34] Huber J. and C. Shipman, (2006), Politics, Delegation, and Bureaucracy. In B. Weingast and D. Wittman (eds), The Handbook for Political Economy, Oxford Uni. Press, 256272.

[35] Hughes, C. W. (2006). "Why Japan Could Revise its Constitution and What it Would Mean for Japanese Security Policy." Orbis 50(4), 725-744.

[36] Kalt. J. P., and M. A. Zupan (1990), "The Apparent Ideological Behavior of Legislators: Testing for Principal-Agent Slack in Political Institutions." Journal of Law and Economics 33, 103-31.

[37] Koessler F. and D. Martimort (2012), Optimal delegation with multi-dimensional decisions, Journal of Economic Theory 147, 1850-1881.

[38] Laussel, D. and J. Resende (2018). Complementary Monopolies with Asymmetric Information: A Private Common Agency Model, Available at SSRN: https://ssrn.com/abstract $=3121668$

[39] Martimort, D., A. Semenov and Stole, L. (2016), A Complete Characterization of Equilibria in Common Agency Screening Games", Working Paper, May 31, 2016. 
[40] Maskin, Eric, and Jean Tirole (2004), The Politician and the Judge: Accountability in Government. The American Economic Review, Vol. 94, No. 4 (Sep., 2004), pp. 10341054.

[41] Matsusaka, J. (2004). For the Many or for the Few: The Initiative, Public Policy, and American Democracy. Chicago. Uni of Chic Press.

[42] McKelvey, R.D (1976). Intransitivities in Multidimensional Voting Models and Some Implications for Agenda Control, Journal of Economic Theory 12, 472-482.

[43] Osborne, M. J. and A. Slivinski (1996). A Model of Political Competition with Citizens Candidates, The Quarterly Journal of Economics 111(1), 65-96.

[44] Persson, Torsten, and Guido Tabellini (2000). Political Economics: Explaining Economic Policy. MIT Press, Cambridge, Massachussetts.

[45] Przeworski, A., S. Stokes and B. Manin (1999), Democracy, Accountability and Representation, Cambridge: Cambridge University Press.

[46] Rogoff, K. (1990). "Equilibrium Political Budget Cycles," American Economic Review, Vol. 80. pp. 21-36.

[47] Rousseau, Jean-Jacques (1762). Du Contrat Social, Amsterdam: Marc-Michel Rey.

[48] Singer, P. (2016), Direct Democracy and Brexit, https://www.projectsyndicate.org/commentary/direct-democracy-and-brexit-by-peter-singer-2016-07.

[49] Stone Sweet, A. (2007). "The Politics of Constitutional Review in France and Europe," I.CON Vol. 5(1), pp. 69-92 doi: 10.1093/icon/mol041.

[50] Stokes, D. E. (1963). "Spatial Models of Party Competition," The American Political Science Review 57(2): 368-377. 
[51] Vladeck, S. I. (2010), The Laws of War as a Constitutional Limit on Military Jurisdiction, J. of National Security Law \& Policy 4(2), 295-342.

[52] Weiss, D. C. (2008). "Nothing Improper? Examining Constitutional Limits, Congressional Action, Partisan Motivation, and Pretextual Justification in U.S. Attorney Removals," Michigan Law Review 107(2), 317-363. 